\title{
Investigations of Ancient Terra-cotta Sarcophagi, Excavated in Enez (Ainos) Turkey, by Instrumental Neutron Activation Analysis
}

\author{
Sevim Akyuz, ${ }^{1, *}$ Tanil Akyuz, ${ }^{1}$ Nuranya M. Mukhamedshina, ${ }^{2}$ Kubilay Balci, ${ }^{3}$ A. Adiba Mirsagatova, ${ }^{2}$ \\ Gulnur Kurap, ${ }^{4}$ Sait Basaran ${ }^{5}$
}

\footnotetext{
1 Physics Department, Science and Letters Faculty, Istanbul Kultur University, Atakoy Campus, Bakirkoy 34156, Istanbul, Turkey

2 Institute of Nuclear Physics, Uzbek Academy of Sciences, 702132, Ulugbek, Tashkent, Uzbekistan

3 Physics Department, Science Faculty, Istanbul University, 34134 Vezneciler, Istanbul, Turkey

${ }^{4}$ Restoration and Conservation of Artefacts Department, Fine Arts Faculty, Mimar Sinan Fine Arts University, Istanbul, Turkey

${ }^{5}$ Restoration and Conservation of Movable Cultural Assets Department, Letters Faculty, Istanbul University, Vezneciler, Istanbul, Turkey

* Corresponding author's e-mail address: s.akyuz@iku.edu.tr
}

RECEIVED: September 29, 2015 * REVISED: November 26, $2015 *$ ACCEPTED: November 26, 2015

THIS PAPER IS DEDICATED TO DR. SVETOZAR MUSIĆ ON THE OCCASION OF HIS 70 ${ }^{\text {TH }}$ BIRTHDAY

Abstract: Ten terra-cotta sarcophagi, together with a terra-cotta aryballos (perfume jar), excavated in Su Terazisi necropolis of Enez-Turkey (Ancient Ainos), were investigated by Instrumental Neutron Activation Analysis (INAA), to determine the concentration of thirty two chemical elements: $\mathrm{Na}, \mathrm{K}, \mathrm{Ca}, \mathrm{Fe}, \mathrm{Sc}, \mathrm{Cr}, \mathrm{Mn}, \mathrm{Co}, \mathrm{Ni}, \mathrm{Cu}, \mathrm{Zn}, \mathrm{As}$, Se, Br, Rb, Sr, Sb, Cs, Ba, La, Ce, Nd, Sm, Eu, Tb, Dy, Yb, Lu, Hf, Ta, Th and U. The dataset was submitted to multivariate statistical analysis. The classification was done by cluster analysis. The results demonstrated the occurrence of two different groups of terra-cotta samples. Group I contains nine sarcophagi and terra-cotta aryballos whereas group II contains only one sample (E09-ST5-M26). High correlations between La and Ce $\left(r^{2}=0.92\right)$, and $\mathrm{U}$ and Th $\left(r^{2}=0.91\right)$ indicated that local clay was used for manufacturing the terra-cotta sarcophagi and aryballos but probably the claybed used for E09-ST5-M26 was different from that of others.

Keywords: ancient terra-cotta sarcophagi, archaeometry, Instrumental neutron activation analysis.

\section{INTRODUCTION}

$\mathbf{E}$ NEZ is a spectacular coastal town with its historical, archaeological and natural values, at the Aegean Sea coast of Edirne. It is known as Ainos in antique periods and is located on the southwest part of Edirne with the Aegean Sea on the west and Greece on the north. The center of the town was built in the ancient times as a Greek colony. ${ }^{[1]}$ The name of Enez comes from a Greek princess called Eneyaz. ${ }^{[1]}$ The town was under the sovereignty of the Roman Empire, Byzantium, republic of Genoa, Ottoman Empire, Russia and Greece, in order.[1] The town was included in the Turkish Republic borders after the 1922. Enez (Ancient Ainos) is one of the most important archaeological sites in Turkey. ${ }^{[2]}$ The excavation center is at the northern coast of the Aegean Sea, at the place of where Antic Hebros (Meric) river meets the sea. The archaeological excavations in Enez have been going on for the last 45 years in a number of areas at this site. ${ }^{2]}$ During the excavations, some cemeteries were also unearthed. The Su Terazisi Necropolis, named for an Ottoman water level in this area, is just to the east of the bridge at the entrance to the city, contains tombs dating from the $6^{\text {th }}$ and $5^{\text {th }}$ centuries BC. At this necropolis, cremation and inhumation burials in various types of tombs have been found.

In our previous studies some ancient terra-cotta sarcophagi excavated in Enez in 2005 and 2008 were investigated by FTIR and XRF techniques. ${ }^{[3-4]}$ In continuation of our studies on terra-cotta sarcophagi unearthed in the excavations of ancient Ainos, in this study, ten rectangular terracotta sarcophagi, together with a terra-cotta aryballos (perfume jar), belonging to $6^{\text {th }}$ and $5^{\text {th }}$ centuries $B C$ and found 
in the fourth, fifth or sixth zones of Su Terazisi necropolis in the 2009 excavations, were investigated by Instrumental Neutron Activation Analysis (INAA). INAA is a very accurate and highly sensitive method for multi-elemental analysis, which has been extensively applied to provenance studies. ${ }^{[5-7]}$ Moreover, INAA, a technique that gives qualitative and quantitative information about rare-earth elements and represents the preferred analytical technique to address questions such as composition of ancient materials and their provenance. The classification of the archaeological findings was done by multivariate statistical analysis.

\section{EXPERIMENTAL}

In this study body samples of ten terra-cotta sarcophagi (E09-ST4-M6; E09-ST4-M9; E09-ST4-M10; E09-ST4-M11; E09-ST6-M13; E09-ST4-M16; E09-ST4-M17; E09-ST4-M19; E09-ST5-M25; E09-ST5-M26) along with a terra-cotta aryballos fragment (perfume jar) (E09-ST5), that were unearthed in the fourth, fifth or sixth zones of the excavation area of the Su-Terazisi (ST) necropolis (abbreviated as ST4, ST5 or ST6, respectively) in 2009, were investigated. All investigated sarcophagi are known as Clazomenian type ${ }^{[8]}$ and have been discovered fragmented in the excavations (see Figure 1). Some of them have egg-frieze decorations at the rim. The photographs of some terra-cotta sarcophagi and the aryballos fragment are shown in Figure 1.

The terra-cotta fragments were analyzed using instrumental neutron activation analysis. The samples were irradiated simultaneously with reference materials from IAEA (SL-1, Soil-7) for 70 hours, at thermal neutron flux density of $6.510^{10} \mathrm{~cm}^{-2} \mathrm{~s}^{-1}$, in the nuclear reactor of Institute of Nuclear Physics, Tashkent, Uzbekistan. Conditions of cooling and measuring were chosen by taking into account of

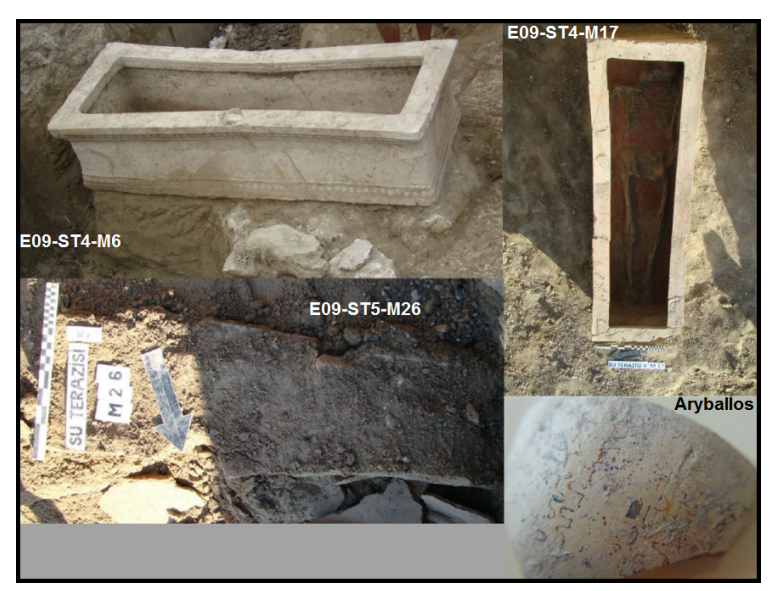

Figure 1. Photographs of some investigated sarcophagi (E09-ST4-M6, E09-ST4-M17, E09-ST5-M26) and terra-cotta aryballos. the half-life time of the elements. ${ }^{[9]}$ For measurement and treatment of the sample spectrum, gamma-spectrometer was used with HPGe coaxial gamma-ray detector (the resolution $1.8 \mathrm{keV}$ at $1332.5 \mathrm{keV}$, relative efficiency $15 \%$ ), charge sensitive preamplifier and multichannel analyzer DSA-1000 with software Genie-2000 (Canberra industries). Uncertainties of the impurity content determination were estimated by the relative standard deviation $\left(S_{r}\right)$, which was calculated from the results of 5 multiple (independent) measurements. It was found to be in the range of 0.07-0.1.

Cluster analysis was performed on INAA results using The Unscrambler CAMO software. ${ }^{[10]}$

\section{RESULTS AND DISCUSSION}

Concentrations of the 32 elements of the sarcophagi and the aryballos fragments were determined by the use of INAA. The analytical results of $\mathrm{Na}, \mathrm{K}, \mathrm{Ca}, \mathrm{Fe}, \mathrm{Sc}, \mathrm{Cr}, \mathrm{Mn}, \mathrm{Co}$, $\mathrm{Ni}, \mathrm{Cu}, \mathrm{Zn}, \mathrm{As}, \mathrm{Se}, \mathrm{Br}, \mathrm{Rb}, \mathrm{Sr}, \mathrm{Sb}, \mathrm{Cs}, \mathrm{Ba}, \mathrm{La}, \mathrm{Ce}, \mathrm{Nd}, \mathrm{Sm}, \mathrm{Eu}, \mathrm{Tb}$, Dy, Yb, Lu, Hf, Ta, Th and $\mathrm{U}$ elements are given in Table 1.

The relative abundance of rare-earths elements (REEs) is peculiar of the geological history of a material and represents the fingerprint of an archeological material. ${ }^{[11,12]}$ It is often used as provenance indicator. The REEs, Hf, Ta, $\mathrm{U}$ and Th elements distributions of the investigated samples are shown in Figure 2. Analysis of the graph of Figure 2 shows that all the samples (except E09-ST5-M26) are featured by a very similar pattern concerning REEs, Hf, Ta, $\mathrm{U}$ and Th elements, suggesting that the common geological source of local clay was used for manufacturing the terracotta sarcophagi and aryballos, but may be two different clay sources were used. Figure 3 shows the scatterplots of all samples projected on axes of $\mathrm{mg} / \mathrm{kg} U$ and $\mathrm{Th}$, and on

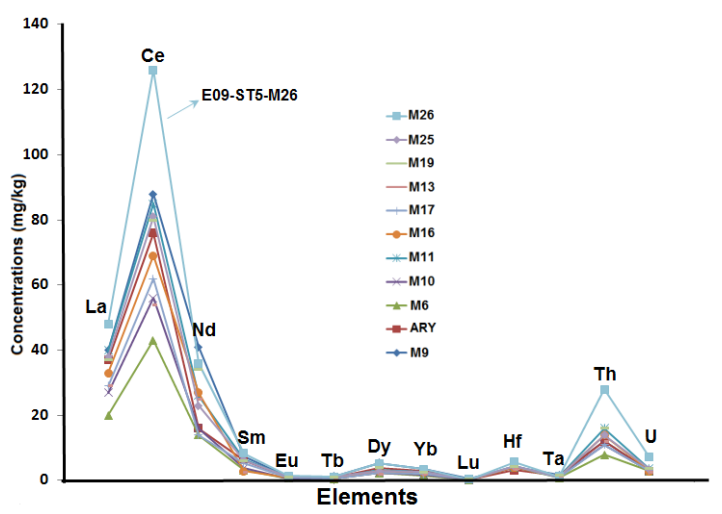

Figure 2. Concentrations of REE, $H f, T a, T h$ and $U$ in terracotta sarcophagi and aryballos fragment. M9 = E09ST4-M9; ARY = aryballos fragment; M6 = E09-ST4-M6; M10 = E09-ST4-M10; M11 = E09-ST4-M11; M16 = E09-ST4-M16; M17 = E09-ST4-M17; M13 = E09-ST6-M13;M19 = E09-ST4M19; M25 = E09-ST5-M25; M26 = E09-ST5-M26. 


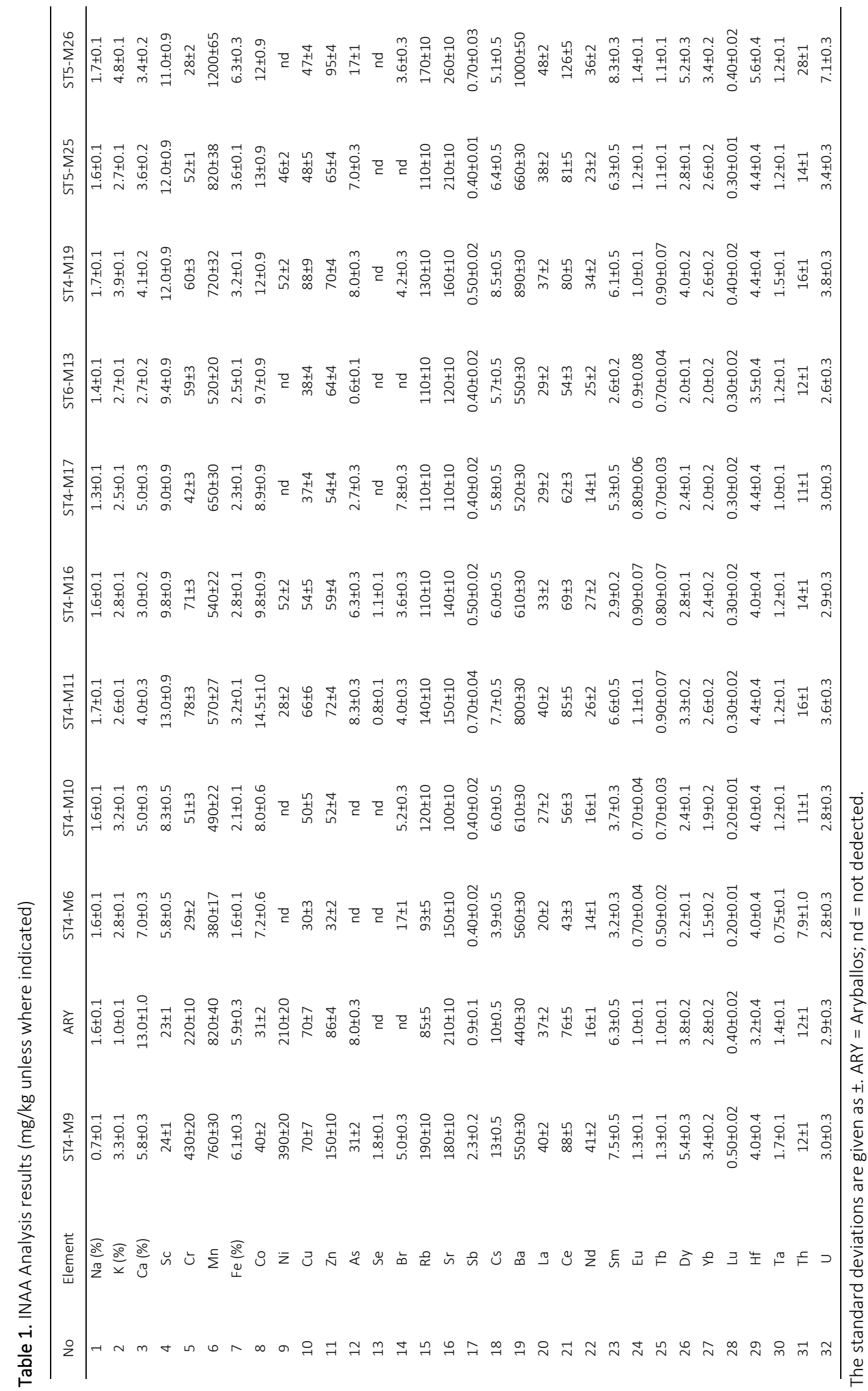



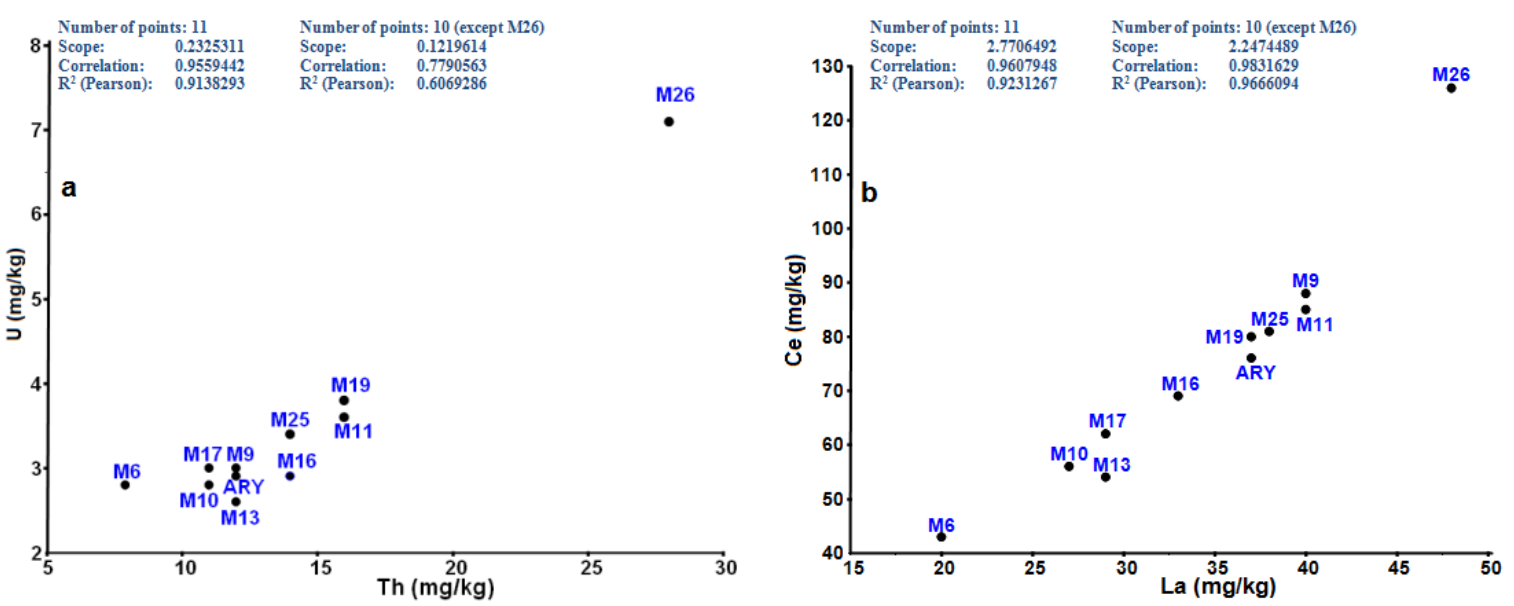

Figure 3. Scatterplots of all samples projected on axes of $\mathrm{mg} / \mathrm{kg} U$ and $\mathrm{Th}(\mathrm{a})$ and on axes of $\mathrm{mg} / \mathrm{kg}$ La and Ce (b). For abbreviations see Figure 2.

axes of $\mathrm{mg} / \mathrm{kg}$ La and Ce. It is known that members of the lanthanide series ( $\mathrm{La}, \mathrm{Ce}$ ) demonstrate strong positive correlations, as do members of the actinide series ( $U$ and $T h$ ). High correlation ( $r^{2}=0.91$ for Th- $U$ and 0.92 for La-Ce) indicates that the raw materials used in terracotta samples originate from the same geological source. The $T h / U$ ratio is known to be characteristic of the geological provenance. ${ }^{[13-14]}$ For all the investigated samples the $T h / U$ ratio ranges from 2.8 to 4.8 . However, although for the sarcophagus E09-ST5-M26, this ratio is 3.9, which is in the range of $\mathrm{Th} / \mathrm{U}$ ratio of the other samples, both $\mathrm{Th}$ and $U$ element concentrations of this sample are relatively high than the others. Moreover, this sample also has relatively high La and Ce concentrations. Thus, sarcophagus E09-ST5-M26

Average linkage clustering using Squared Euclidean distance

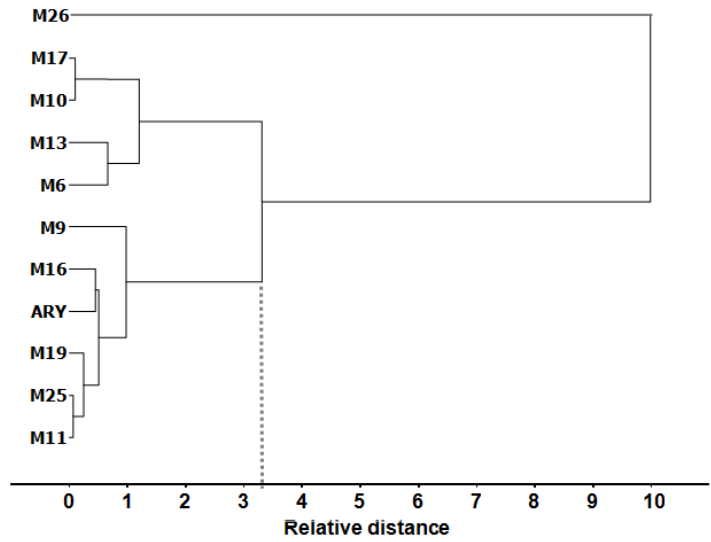

Figure 4. The dendrogram of squared Euclidian distances, average linkage method, calculated using INAA data of REE, $\mathrm{Hf}, \mathrm{Ta}, \mathrm{U}$ and Th elements (in $\mathrm{mg} / \mathrm{kg}$ ) for investigated samples. For abbreviations see Figure 2. with a distinctive composition seems to have been produced from a different local clay deposit, than the others.

The compositional data from REE, Hf, Ta, $\mathrm{U}$ and Th elements were also processed statistically to check their homogeneity. The dendrogram of squared Euclidian distances, average linkage method, calculated using INAA data of REE, Hf, Ta, $\mathrm{U}$ and Th elements for the investigated samples is given in Figure 4. As seen in this figure, all the samples, except E09-ST5-M26 show similarity.

In this work compositional analysis of the investigated samples were also performed. Cluster analysis was further employed to compositional data acquired through INAA. The cluster analysis was carried out on base-10 logarithms of the concentrations of all chemical elements that do not have undetermined data (except $\mathrm{Ni}, \mathrm{As}$, Se, $\mathrm{Br}$, see Table 1). The chemical elements of the terrace-cotta samples are divided into "major" and "minor/trace" elements. Major elements are measured in \%, as like as $\mathrm{Na}, \mathrm{K}, \mathrm{Ca}, \mathrm{Fe}$. Minor or trace elements are measured in $\mathrm{mg} / \mathrm{kg}$. In a multivariate analysis, we have to use the same unit (e.g. $\mathrm{mg} / \mathrm{kg}$ ). But when all the elements are transferred in one unit, the major elements occur in much greater amounts than the trace elements. As a result only the major elements affect the analysis results. This may become a problem in multivariate techniques that are based on distance coefficients, because the variable with the greatest magnitude will have the greatest influence on the outcome. For this reason, the elemental concentration values were transformed to log base 10 values before performing multivariate statistical analysis on the data. This compensated for the differences in magnitude between minor and trace elements, and normalized element distribution. ${ }^{[5,6]}$ Cluster analysis was performed on 28 variables, using the Log-(concentration) values of the chemical elements that do not have undetermined data, using squared Euclidian distance and average 


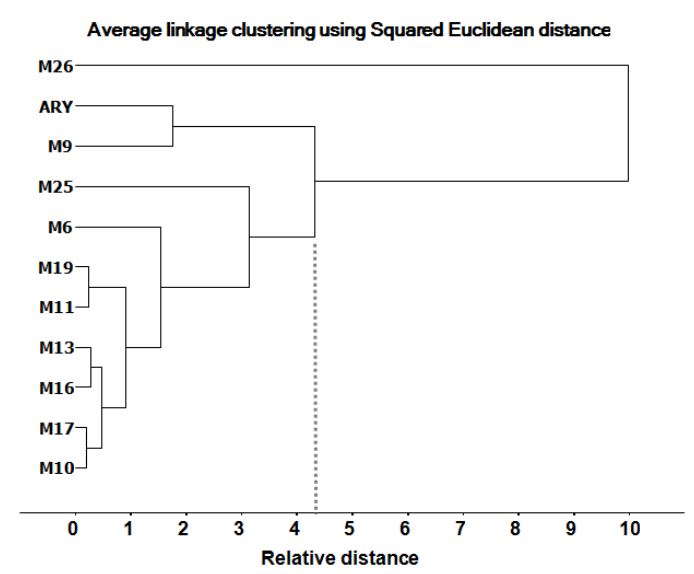

Figure 5. The dendrogram of squared Euclidian distances, average linkage method, calculated using Log-(concentration) values of the chemical elements (except $\mathrm{Ni}, \mathrm{As}$, Se, Br). For abbreviations see Figure 2 .

linkage method. Figure 5 shows the dendrogram explains two groups of terra-cotta samples. Group I contains E09ST4-M6, E09-ST4-M9, E09-ST4-M10, E09-ST4-M11, E09ST6-M13, E09-ST4-M16, E09-ST4-M17, E09-ST4-M19, E09ST5-M25 and terra-cotta aryballos. Group II contains only one sample (E09-ST5-M26). The E09-ST5-M26 sample is found to be dissimilar from the others by 3.3-4.3 relative Euclidian distance values in the cluster analyses performed on both the REE, Hf, Ta, Th, U elements (see Figure 4) and all determined concentrations (see Figure 5).

Terra-cotta composition will depend both on the clay source and the recipe used to prepare the clay paste. Enez area is famous by clay deposits. ${ }^{[15]}$ The compositional variability within the different clay sources in the same area is expected to be smaller than the variability those originated in different regions. ${ }^{[13,15]}$ For this reason we propose that local clay was used for manufacturing the terra-cotta sarcophagi and aryballos, but probably the claybed used for E09-ST5M26 was different from that of all the others.

\section{CONCLUSION}

In this study, the body samples of ten terra-cotta sarcophagi and a terra-cotta aryballos, unearthed in Su Terazisi necropolis of ancient Ainos (Enez) Turkey, were investigated by INAA. The elemental concentrations of $\mathrm{Na}, \mathrm{K}, \mathrm{Ca}, \mathrm{Fe}, \mathrm{Sc}$, $\mathrm{Cr}, \mathrm{Mn}, \mathrm{Co}, \mathrm{Ni}, \mathrm{Cu}, \mathrm{Zn}$, As, Se, Br, Rb, Sr, Sb, Cs, Ba, La, Ce, $\mathrm{Nd}, \mathrm{Sm}, \mathrm{Eu}, \mathrm{Tb}, \mathrm{Dy}, \mathrm{Yb}, \mathrm{Lu}, \mathrm{Hf}, \mathrm{Ta}$, Th and $\mathrm{U}$ elements were determined. The relative abundance of rare-earths elements (REE) was found to be similar, indicating that local clay was used for manufacturing the terra-cotta sarcophagi and aryballos. The cluster analyses performed separately both on the REE, $\mathrm{Hf}, \mathrm{Ta}, \mathrm{Th}, \mathrm{U}$ elements and all determined concentrations, demonstrated the occurrence of two different groups of terra-cotta samples. Group I contains nine sarcophagi and terra-cotta aryballos, whereas, group II contains only one sample (E09-ST5-M26). Results suggest that local clay was used for manufacturing the terra-cotta sarcophagi and aryballos but probably the claybed used for E09-ST5-M26 was different from that used for the manufacture of all other sarcophagi.

\section{REFERENCES}

[1] E. E. Sisman, A. Korkut, B. Etli, M. Cilek, J. Environ. Product. Ecol. 2006, 7(4), 860.

[2] S. Basaran, Excavation and Restoration work at Enez (Ainos) in 2001, in S. Donmez, (Ed.), "Anatolian Research" Istanbul University, Letters Faculty press, Istanbul 2002, pp. 59 (in Turkish).

[3] G. Kurap, S. Akyuz, T. Akyuz, S. Basaran, B. Cakan, J. Mol. Struc. 2010, 976, 161.

[4] S. Akyuz, T. Akyuz, G. Kurap, S. Basaran, B. UcarCakan, I. Kocabas, Asian J. Chem. 2011, 23, 3235.

[5] G. A. De La Fuente, J. R. Ferguson, M. D. Glascock, Archaeometry, 2015, 57, 1.

[6] J. B. Tandoh, Y. Bredwa-Mensah, S. B. Dampare, E. H. K. Akaho, B. J. B. Nyarko, Nucl. Instr. and Meth. B 2009, 267, 1924.

[7] M. I. Dias, M. I. Prudêncio, Archaeometry, 2007, 49, 383.

[8] R. M. Cook, Clazomenian sarcophagi 1981, Forschungen zur antiken Keramik. 2. Reihe, Kerameus; Bd. 3. Philipp von Zabern, Mainz/Rhein (Germany).

[9] S. Akyuz, T. Akyuz, N. M. Mukhamedshina, A. A. Adiba, S. Basaran, B. Cakan, Spectrochim. Acta B 2012, 71-72, 75.

[10] K.H. Esbensen, Multivare Data Analysis-In practice, CAMO Process AS, Norway, ISBN 82-993330-3-2, 2004.

[11] H. Mommsen, J. Radioanal. Nucl. Chem., 2001, 247, 657.

[12] P. Cardiano, S. Ioppolo, C. De Stefano, A. Pettignano, S. Sergi, P. Piraino, Anal. Chim. Acta 2004, 519, 103.

[13] A. Hein, P. M. Day, P. S. Quinn, V. Kilikoglou, Archaeometry 2004, 46, 357.

[14] H. Basu, K. M. Kumar, S. Paneerselvam, A. Chaki, J. Geo. Soc. India, 2009, 74, 318.

[15] N. Caliskan, XRD Study of Enez Clay and Its Interaction with Acids, PhD Thesis, Inonu University, Malatya-Turkey, 1986. 